\title{
TOPOSSEQÜÊNCIAS DE LATOSSOLOS ORIGINADOS DE ROCHAS BASÁLTICAS NO PARANÁ. I - MINERALOGIA DA FRAÇÃO ARGILA ${ }^{(1)}$
}

\author{
André Ademir Ghidin ${ }^{(2)}$, Vander de Freitas Melo ${ }^{(3)}$, Valmiqui Costa \\ Lima $^{(3)} \&$ Jane Maria Jonasson Costa Lima ${ }^{(3)}$
}

\begin{abstract}
RESUMO
Com o objetivo de estudar o efeito de diferentes posições do relevo e materiais de origem sobre as características mineralógicas da fração argila dos solos, foram estudadas duas toposseqüências de Latossolos (Latossolo Bruno ácrico - LBw e Latossolo Vermelho distroférrico - LVdf) no Estado do Paraná. A fração argila foi estudada por difratometria de raios $\mathrm{X}$, análise termodiferencial, análise termogravimétrica diferencial e análises químicas. Os teores totais de $\mathrm{Si}, \mathrm{Al}$ e Fe foram determinados após a digestão das amostras com água régia (mistura 3:1 de $\mathrm{HCl} 36 \%$ : $\mathrm{HNO}_{3} 68 \%$ ). Nos extratos resultantes da extração com oxalato de amônio ácido (OAA) e ditionito-citrato-bicarbonato (DCB), determinaram-se os teores de Fe e Al. O teor de Si no material de origem e a posição dos perfis na paisagem foram importantes na definição da mineralogia da fração argila. $O$ LBw e o LVdf foram classificados como caulinítico/goethítico e gibbsítico/ hematítico, respectivamente. Verificaram-se maiores teores de $\mathrm{SiO}_{2}$ total e de caulinita $(\mathrm{Ct})\left(373,3\right.$ a $\left.574,3 \mathrm{~g} \mathrm{~kg}^{-1}\right)$ para o $\mathrm{LBw}$ nos horizontes mais profundos (Bw2) e nos perfis mais baixos na toposseqüência. A maior presença de água associada à drenagem limitada no perfil 4 do LBw (ponto mais baixo da toposseqüência) favoreceu os maiores teores de óxidos de $\mathrm{Fe}$ e $\mathrm{Al}$ de baixa cristalinidade (OAA) e os menores teores de $\mathrm{Fe}_{2} \mathrm{O}_{3}$ DCB (óxidos de $\mathrm{Fe}$ mais cristalinos). De maneira geral, não houve variação consistente nos valores dos atributos cristalográficos da hematita e goethita de acordo com a profundidade do solo e posição do perfil na toposseqüência. Os menores índices de cristalinidade da $\mathrm{Ct}$ foram verificados nas amostras do $\mathrm{LVdf}$, associados ao maior teor de Fe total no solo $\left(\mathrm{r}=\mathbf{0 , 7 9 ^ { * * }}\right)$. O menor crescimento da gibbsita [menor valor do diâmetro médio do cristal no domínio (110)] foi observado no perfil 4 do LBw (posição mais baixa da toposseqüência).
\end{abstract}

Termos de indexação: silício, caulinita, óxidos de ferro, gibbsita, características cristalográficas.

\footnotetext{
(1) Parte da Tese da Tese de Mestrado do primeiro autor. Recebido para publicação em julho de 2004 e aprovado em março de 2006.

(2) Professor do Curso Gestão Ambiental, Faculdade Palas Atena - FPA. CEP 85560-000 Chopinzinho (PR). E-mail: ghidin@chnet.com.br

(3) Professor do Departamento de Solos, Universidade Federal do Paraná - UFPR. Rua dos Funcionários 1540, CEP 80035-050, Juvevê, Curitiba (PR). E-mail: vanderfm@ufpr.br; valmiqui@ufpr.br
} 


\title{
SUMMARY: OXISOL TOPOSEQUENCES DEVELOPED FROM BASALTIC ROCKS IN PARANÁ STATE, BRAZIL. I - CLAY FRACTION MINERALOGY
}

\begin{abstract}
Two Oxisol (Red-Yellow Latosol - LBw and Dusky Red Latosol - LVdf) toposequences in Paraná State, Brazil, were evaluated regarding the effect of different relief positions and parent material on mineralogical characteristics of the soil clay fraction. The clay fraction was investigated by $X$-ray diffraction, differential thermal analysis, thermogravimetry, and chemical analysis. Total Si, Al and Fe contents were determined after clay sample digestion with a $3: 1$ mixture of $36 \% \mathrm{HCl}$ and $68 \% \mathrm{HNO}_{3}$ acids. The $\mathrm{Fe}$ and $\mathrm{Al}$ contents were determined in acid ammonium oxalate $(A A O)$ and citrate-bicarbonate-dithionite $(C B D)$ extracts. The concentration of Si in the parent material and the position of the profile in the landscape were important in defining the clay fraction composition. LBw and LVdf were classified as kaolinitc/goethitic and gibbsitic/hematitic, respectively. Higher total $\mathrm{SiO}_{2}$ and kaolinite (Ka) contents (373.3 to $574.3 \mathrm{~g} \mathrm{~kg}^{-1}$ ) were observed in the deeper horizons (Bw2) and lower profile positions in the toposequence for the $L B w$. The higher water content and smaller soil permeability in LBw profile 4 (lowest position in the landscape) resulted in higher concentration of amorphous $\mathrm{Al}$ and $\mathrm{Fe}$ oxide (AAO) and reduced concentration of more crystalline Fe oxide (CDB). In general, the crystallographic characteristics of hematite and goethite were not influenced by soil depth and profile position. The lowest crystallinity indexes of Ka were found in the LVdf samples, and were related to the higher concentration of total Fe $\left(r=0.70^{* *}\right)$. The lowest gibbsite growth (smallest mean crystal diameter in the (110) direction) was observed in the LBw profile 4 (lowest position in the toposequence).
\end{abstract}

Index terms: silicon, kaolinite, iron oxides, gibbsite, crystallographic characteristics.

\section{INTRODUÇÃO}

Os solos existentes na paisagem refletem sua história, desde o primeiro instante de sua gênese até o presente, como conseqüência da atuação de cinco fatores (material de origem, clima, relevo, tempo e organismos) e quatro processos (adição, remoção, translocação e transformação). Fenômenos físicos e químicos diferenciados atuam no material de origem, motivando progressivas transformações e determinando as características morfológicas, físicas, químicas e mineralógicas dos solos formados.

Para o processo evolutivo do solo, a participação do relevo também é importante, visto que o relevo, de maneira geral, influencia a quantidade de água incorporada no solo, acelerando as reações químicas do intemperismo, promovendo o transporte de sólidos ou de materiais em solução, produzindo efeitos que se traduzem em diferentes tipos de solos, nas diversas posições das toposseqüências (Carvalho, 1981). Curi \& Franzmeier (1984), estudando uma toposseqüência de Latossolos originários do basalto, observaram que os solos das posições mais inclinadas eram menos intemperizados, e que, na posição mais alta, eram mais oxídicos (hematita e gibbsita) e, nos locais mais baixos, predominava a caulinita na fração argila.

Os diferentes teores de minerais da fração argila na toposseqüência podem ser atribuídos à ação da drenagem, onde a percolação da água no perfil remove o Si das partes mais altas (topo) carreandoo para as partes mais baixas do relevo (Hsu, 1989). Com a perda de $\mathrm{Si}$, chegando a concentração do elemento ser próxima a zero na solução do solo, a formação da gibbsita é favorecida. Já nas partes mais baixas, a maior concentração de Si favorece sua recombinação com $\mathrm{Al}$ e formação da caulinita (Antonello, 1983).

A formação dos óxidos de Fe também é fortemente influenciada pela dinâmica da água ao longo da toposseqüência. Além da lixiviação de Si, a água de drenagem promove a concentração de ácidos húmicos, principalmente daqueles de baixo peso molecular, nas partes mais baixas, o que favorece a formação da goethita (Schwertmann \& Taylor, 1989). Já nas partes mais altas do relevo, com menor umidade e maior temperatura, verificase a formação preferencial de hematita, graças, principalmente, à facilidade de desidratação da ferriidrita (Kämpf \& Schwertmann, 1983).

Adicionalmente à quantidade e proporção dos minerais na fração argila dos solos ao longo da toposseqüência, as suas características cristalográficas, como, por exemplo, cristalinidade, diâmetro médio do cristal, substituição isomórfica de elementos na estrutura e superfície específica, podem apresentam efeito pronunciado nas características físico-químicas dos solos, além de 
indicar a natureza dos ambientes pedogenéticos (Fitzpatrick \& Schwertmann, 1982; Schwertmann, 1988; Kämpf et al., 1988a,b).

O objetivo deste trabalho foi estudar o efeito de diferentes posições no relevo (toposseqüência) e diferentes materiais de origem (rochas basálticas) na mineralogia da fração argila de duas classes de Latossolos, incluindo características cristalográficas dos minerais.

\section{MATERIAL E MÉTODOS}

\section{Descrição geral das áreas e amostragem dos solos}

As áreas estudadas pertencem aos Municípios de Guarapuava e Cascavel (PR), localizadas no Terceiro Planalto Paranaense, fazendo parte do Planalto de Guarapuava, situados entre os Rios Iguaçu e Piquiri, limitando-se a oeste pelo rio Paraná e a leste pela serra da Boa Esperança (Maack, 1968). De maneira geral, o Terceiro Planalto é a região fisiográfica paranaense mais simples pelas suas formas e estruturas, com relevo levemente ondulado e chapadas de encostas suaves (Bigarella et al., 1994).

Segundo Schneider (1970), em área próxima a Cascavel, a rocha é o basalto vacuolar, o qual apresenta coloração preta, brilho resinoso, com predomínio de plagioclásio, piroxênios, magnetita e presença de alguns secundários (cloritas esverdeadas e óxidos e hidróxidos de Fe). Já em Guarapuava, foi identificado o andesi-basalto pórfiro (rocha mais ácida), o qual apresenta coloração cinzaclara a cinza escura, com predomínio de plagioclásio (andesina), piroxênio (hiperstênio e augita), opacos (magnetita) e quartzo.

A toposseqüência no Município de Guarapuava localizou-se no Parque Ambiental das Araucárias, situado na latitude $25^{\circ} 21^{\prime} 50^{\prime \prime}$ Sul e longitude $51^{\circ} 28^{\prime} 33^{\prime \prime}$ Oeste, com altitude de 1.068 m. Já a toposseqüência do Município de Cascavel localizouse no Parque Ambiental de Cascavel, situado na latitude $24^{\circ} 27^{\prime} 21^{\prime \prime}$ Sul e longitude $53^{\circ} 27^{\prime} 19^{\prime \prime}$ Oeste, com altitude de $781 \mathrm{~m}$. As toposseqüências apresentaram comprimento médio da rampa de $400 \mathrm{~m}$. Foram abertas quatro trincheiras em cada área, distribuídas uniformemente da parte mais alta até à parte mais baixa da paisagem (Quadro 1). Após a abertura das trincheiras, os solos foram morfologicamente descritos (Quadro 1) segundo Lemos \& Santos (1996), e as amostras coletadas em todos os horizontes dos perfis foram submetidas a análises químicas ( $\mathrm{pH}$, teores trocáveis de $\mathrm{Ca}, \mathrm{Mg}$, $\mathrm{K}, \mathrm{Al}$, acidez potencial e $\mathrm{C}$ orgânico - Pavan et al., 1992) e física (análise granulométrica - Embrapa, 1997). Os teores totais dos elementos e as determinações mineralógicas foram realizadas apenas nos horizontes Bw1 e Bw2. Os solos foram classificados (Embrapa, 1999) como Latossolo Bruno ácrico húmico (LBw) (toposseqüência de Guarapuava) e Latossolo Vermelho distroférrico húmico (LVdf) (toposseqüência de Cascavel).

\section{Preparação das amostras e separação das frações do solo para análises químicas e mineralógicas}

As amostras foram tratadas com hipoclorito de sódio para remoção de matéria orgânica e com $\mathrm{NaOH}$ 0,2 $\mathrm{mol} \mathrm{L}^{-1}$ para dispersão das partículas (Jackson, 1979). Após esses tratamentos prévios, a fração areia foi retida em peneira de 0,05 $\mathrm{mm}$ e as frações argila e silte foram recolhidas em provetas de $1.000 \mathrm{~mL}$ e separadas por sedimentação com base na lei de Stokes (Gee \& Bauder, 1986).

\section{Determinação dos teores totais de $\mathrm{Si}, \mathrm{Al}$ e $\mathrm{Fe}$ da fração argila}

Amostras em duplicatas com aproximadamente $100 \mathrm{mg}$, pesadas em balança de precisão de 0,0001 g, foram colocadas em vasos de digestão de teflon na presença de $4 \mathrm{~mL}$ de água régia (mistura $3: 1$ de $\mathrm{HCl}$ $36 \%: \mathrm{HNO}_{3} 68 \%$ ) e $3 \mathrm{~mL}$ de $\mathrm{HF}$ (40\%). Em seguida, os vasos foram fechados e submetidos à digestão por microondas num equipamento Provecto Analítica DGT - 100 plus, com $1.000 \mathrm{~W}$ de potência.

Ajustou-se o equipamento para que a digestão ocorresse em cinco passos, com tempo e fornecimento de potências variáveis, da seguinte forma: $1^{\circ}$ passo - 5 min a $800 \mathrm{~W} ; 2^{\circ}$ passo -5 min a $530 \mathrm{~W} ; 3^{\circ}$ passo - 5 min a $650 \mathrm{~W} ; 4^{\circ}$ passo - 5 min a $530 \mathrm{~W}$, e $5^{\circ}$ passo - 5 min a $0 \mathrm{~W}$. Após esse período, os vasos foram retirados do forno microondas e, depois de resfriados, foram abertos.

A solução resultante foi transferida para frascos de polietileno, onde foram adicionados $5 \mathrm{~mL}$ de solução saturada de $\mathrm{H}_{3} \mathrm{BO}_{3}$ para neutralização dos resíduos de $\mathrm{HF}$. Os teores totais de $\mathrm{Al}$ e $\mathrm{Fe}$ foram determinados por espectrofotometria de absorção atômica. Já os teores de Si foram determinados, após ataque sulfúrico das amostras de solo (Embrapa, 1997), por gravimetria em decorrência de problemas analíticos na dosagem do elemento por absorção atômica.

\section{Análises mineralógicas na fração argila}

Para identificar os minerais por difratometria de raios X (DRX), amostras da fração argila foram montadas em placa de Koch (amostras não orientadas) (Besoian, 1985). Os difratogramas foram obtidos em goniômetro vertical Philips, modelo PW1050/70, com velocidade de $1^{\circ} 2 \theta / \mathrm{min}$ e amplitude de 4 a $65^{\circ} 2 \theta$. O difratômetro, equipado com tubo de $\mathrm{Cu}$, filtro de $\mathrm{Ni}$ e utilizando radiação $\mathrm{CuK} \alpha$, foi operado a $20 \mathrm{~mA}$ e $40 \mathrm{kV}$. 
Quadro 1. Características morfológicas dos perfis de $\operatorname{solos}^{(1)}$

\begin{tabular}{|c|c|c|c|c|c|c|c|c|c|c|}
\hline \multirow{2}{*}{ Amostra } & \multirow{2}{*}{ Perfil/classe } & \multirow{2}{*}{ Hor. } & \multirow{2}{*}{ Prof. } & \multirow{2}{*}{ Situação( ${ }^{(2)}$} & \multirow{2}{*}{ Declive $^{(3)}$} & \multirow{2}{*}{ Drenagem $^{(4)}$} & \multirow{2}{*}{$\begin{array}{l}\text { Cor úmido } \\
\text { (Munsell) }\end{array}$} & \multirow{2}{*}{ Estrutura(6) } & \multicolumn{2}{|c|}{ Consistência } \\
\hline & & & & & & & & & Úmido $^{(7)}$ & Molhado( $^{(8)}$ \\
\hline & & & $\mathrm{cm}$ & & $\%$ & & & & & \\
\hline $\begin{array}{l}1 \\
2\end{array}$ & $\begin{array}{l}\text { P1 LBw } \\
\text { P1 LBw }\end{array}$ & $\begin{array}{l}\text { Bw1 } \\
\text { Bw2 }\end{array}$ & $\begin{array}{r}58-120 \\
120-200\end{array}$ & TSE & $3-5$ & $\mathrm{AD}$ & $\begin{array}{l}5 \mathrm{YR} 5 / 6 \\
2,5 \mathrm{YR} 4 / 8\end{array}$ & $\begin{array}{l}\mathrm{F}, \mathrm{MP}, \mathrm{G} \\
\mathrm{M}, \mathrm{P}, \mathrm{BS}\end{array}$ & $\begin{array}{l}\text { MF } \\
\text { F }\end{array}$ & $\begin{array}{l}\mathrm{Pl} / \mathrm{Pe} \\
\mathrm{LPl} / \mathrm{Pe}\end{array}$ \\
\hline $\begin{array}{l}3 \\
4\end{array}$ & $\begin{array}{l}\text { P2 LBw } \\
\text { P2 LBw }\end{array}$ & $\begin{array}{l}\mathrm{Bw} 1 \\
\mathrm{Bw} 2\end{array}$ & $\begin{array}{r}50-110 \\
110-200\end{array}$ & TMSE & $4-5$ & $\mathrm{AD}$ & $\begin{array}{l}5 \mathrm{YR} 4 / 6 \\
2,5 \mathrm{YR} 5 / 6\end{array}$ & $\begin{array}{l}\mathrm{M}, \mathrm{MP}, \mathrm{G} \\
\mathrm{M}, \mathrm{MP}, \mathrm{BS}\end{array}$ & $\begin{array}{l}\text { F } \\
\text { FI }\end{array}$ & $\begin{array}{l}\mathrm{Pl} / \mathrm{Pe} \\
\mathrm{LPl} / \mathrm{Pe}\end{array}$ \\
\hline $\begin{array}{l}5 \\
6\end{array}$ & $\begin{array}{l}\text { P3 LBw } \\
\text { P3 LBw }\end{array}$ & $\begin{array}{l}\text { Bw1 } \\
\text { Bw2 }\end{array}$ & $\begin{array}{r}54-110 \\
110-200\end{array}$ & TME & 5 & $\mathrm{AD}$ & $\begin{array}{l}5 \mathrm{YR} 5 / 4 \\
2,5 \mathrm{YR} 4 / 8\end{array}$ & $\begin{array}{l}\mathrm{F}, \mathrm{P}, \mathrm{G} / \mathrm{BS} \\
\mathrm{M}, \mathrm{MP}, \mathrm{BS}\end{array}$ & $\begin{array}{l}\text { MF } \\
\text { F }\end{array}$ & $\begin{array}{l}\mathrm{Pl} / \mathrm{Pe} \\
\mathrm{Pl} / \mathrm{Pe}\end{array}$ \\
\hline $\begin{array}{l}7 \\
8\end{array}$ & $\begin{array}{l}\text { P4 LBw } \\
\text { P4 LBw }\end{array}$ & $\begin{array}{l}\mathrm{Bw} 1 \\
\mathrm{Bw} 2\end{array}$ & $\begin{array}{l}107-160 \\
160-210\end{array}$ & TIE & 5 & $\mathrm{DM} / \mathrm{DI}$ & $\begin{array}{c}\text { 5YR 5/6 } \\
\text { Variegada }^{(5)}\end{array}$ & $\begin{array}{l}\mathrm{M}, \mathrm{MP}, \mathrm{BS} \\
\mathrm{M}, \mathrm{P}, \mathrm{BS}\end{array}$ & $\begin{array}{l}\text { MF } \\
\text { FI }\end{array}$ & $\begin{array}{l}\mathrm{Pl} / \mathrm{Pe} \\
\mathrm{Pl} / \mathrm{Pe}\end{array}$ \\
\hline $\begin{array}{r}9 \\
10\end{array}$ & $\begin{array}{l}\text { P5 LVdf } \\
\text { P5 LVdf }\end{array}$ & $\begin{array}{l}\mathrm{Bw} 1 \\
\mathrm{Bw} 2\end{array}$ & $\begin{array}{r}60-153 \\
153-210\end{array}$ & TSE & $3-4$ & $\mathrm{AD}$ & $\begin{array}{l}10 \mathrm{R} 4 / 6 \\
10 \mathrm{R} 4 / 8\end{array}$ & $\begin{array}{l}\mathrm{F}, \mathrm{MP}, \mathrm{G} \\
\mathrm{M}, \mathrm{MP}, \mathrm{BS}\end{array}$ & $\begin{array}{l}\mathrm{F} \\
\mathrm{F}\end{array}$ & $\begin{array}{l}\mathrm{Pl} / \mathrm{Pe} \\
\mathrm{MPl} / \mathrm{MPe}\end{array}$ \\
\hline $\begin{array}{l}11 \\
12\end{array}$ & $\begin{array}{l}\text { P6 LVdf } \\
\text { P6 LVdf }\end{array}$ & $\begin{array}{l}\text { Bw1 } \\
\text { Bw2 }\end{array}$ & $\begin{array}{r}65-142 \\
142-177\end{array}$ & TMSE & $4-5$ & $\mathrm{AD}$ & $\begin{array}{l}\text { 10R } 4 / 6 \\
10 \mathrm{R} 4 / 8\end{array}$ & $\begin{array}{l}\mathrm{F}, \mathrm{P}, \mathrm{G} \\
\mathrm{M}, \mathrm{P}, \mathrm{BS}\end{array}$ & $\begin{array}{l}\mathrm{MF} \\
\mathrm{F}\end{array}$ & $\begin{array}{l}\mathrm{Pl} / \mathrm{Pe} \\
\mathrm{Pl} / \mathrm{Pe}\end{array}$ \\
\hline $\begin{array}{l}13 \\
14\end{array}$ & $\begin{array}{l}\text { P7 LVdf } \\
\text { P7 LVdf }\end{array}$ & $\begin{array}{l}\mathrm{Bw} 1 \\
\mathrm{Bw} 2\end{array}$ & $\begin{array}{r}67-145 \\
145-176\end{array}$ & TME & $5-6$ & $\mathrm{AD}$ & $\begin{array}{l}2,5 \mathrm{YR} 3 / 6 \\
10 \mathrm{R} 4 / 6\end{array}$ & $\begin{array}{l}\mathrm{M}, \mathrm{MP}, \mathrm{BS} \\
\mathrm{M}, \mathrm{MP}, \mathrm{BS}\end{array}$ & $\begin{array}{l}\text { F } \\
\text { FI }\end{array}$ & $\begin{array}{l}\mathrm{Pl} / \mathrm{Pe} \\
\mathrm{Pl} / \mathrm{Pe}\end{array}$ \\
\hline $\begin{array}{l}15 \\
16\end{array}$ & $\begin{array}{l}\text { P8 LVdf } \\
\text { P8 LVdf }\end{array}$ & $\begin{array}{l}\mathrm{Bw} 1 \\
\mathrm{Bw} 2\end{array}$ & $\begin{array}{r}58-107 \\
107-160\end{array}$ & TIE & 8 & $\mathrm{AD}$ & $\begin{array}{l}2,5 \mathrm{YR} 4 / 6 \\
10 \mathrm{R} 4 / 6\end{array}$ & $\begin{array}{l}\mathrm{F}, \mathrm{MP}, \mathrm{BS} \\
\mathrm{M}, \mathrm{P}, \mathrm{BS}\end{array}$ & $\begin{array}{l}\mathrm{F} \\
\mathrm{F}\end{array}$ & $\begin{array}{l}\mathrm{Pl} / \mathrm{Pe} \\
\mathrm{Pl} / \mathrm{Pe}\end{array}$ \\
\hline
\end{tabular}

(1) Descrição morfológica, segundo Lemos \& Santos (1996). Classificação dos solos (Embrapa, 1999): LBw - Latossolo Bruno ácrico húmico, LVdf - Latossolo Vermelho distroférrico húmico. ${ }^{(2)}$ Situação - posição do perfil na paisagem: TSE, TMSE, TME, TIE - terço superior, médio/superior, médio e inferior de elevação, respectivamente. ${ }^{(3)}$ Declive local. ${ }^{(4)}$ Drenagem: AD - acentuadamente drenado, DM/DI - drenagem moderada/imperfeita. ${ }^{(5)}$ Cor variegada (10YR 7/3 - 7,5YR 5/6 - 2,5YR 5/8) associada à presença de mosqueado comum 5\% pequena/distinta. ${ }^{(6)}$ Estrutura: grau de desenvolvimento (F - forte, M - moderado), tamanho (MP - muito pequeno, $\mathrm{P}$ pequeno), tipo (G - granular, BS - bloco subangular). ${ }^{(7)}$ Consistência no estado úmido: MF - muito friável, F - friável, FI - firme. ${ }^{(8)}$ Consistência no estado molhado: Pl - plástico, Pe - pegajoso, LPl - ligeiramente plástico, MPl - muito plástico, MPe - muito pegajoso.

Foram realizados tratamentos adicionais para diferenciar os minerais secundários do tipo 2:1 da fração argila (Whittig \& Allardice, 1986): saturação por $\mathrm{Mg}$, saturação por $\mathrm{Mg}$ e solvatação com glicerol, saturação por $\mathrm{K}$ e secagem ao ar, saturação por $\mathrm{K}$ e secagem a $550{ }^{\circ} \mathrm{C}$. Após os tratamentos, as amostras foram montadas em lâminas de vidro, utilizando-se a técnica do esfregaço (amostras orientadas), e analisadas por DRX, numa amplitude de 3 a $15^{\circ} 2 \theta$.

Para determinar os teores e a composição química dos óxidos de Fe de baixa e alta cristalinidade, foram utilizados o método do oxalato de amônio $0,2 \mathrm{~mol} \mathrm{~L} \mathrm{~L}^{-1}$, pH 3,0 (OAA) (McKeague, 1978) e o do ditionitocitrato-bicarbonato (DCB) (Mehra \& Jackson, 1960), respectivamente, conforme detalhes apresentados por Melo et al. (2001b). Após as extrações, os teores de $\mathrm{Fe}$ e $\mathrm{Al}$ foram determinados por espectrofotometria de absorção atômica.

Adicionalmente, os óxidos de Fe mais cristalinos (goethita - Gt e hematita - Hm) foram estudados por DRX em amostras da fração argila concentradas pela remoção de caulinita $(\mathrm{Ct})$ e gibbsita $(\mathrm{Gb})$ por meio da fervura com $\mathrm{NaOH} 5 \mathrm{~mol} \mathrm{~L}^{-1}$, pelo período de $1,5 \mathrm{~h}$ em banho-de-areia a $250{ }^{\circ} \mathrm{C}$ (Norrish \& Taylor, 1961; Singh \& Gilkes, 1991). Para evitar a dissolução de óxidos de Fe com alta substituição isomórfica de Fe por Al (Kämpf \& Schwertmann, 1982), foi acrescentado metassilicato de sódio pentaidratado $\left(\mathrm{Na}_{2} \mathrm{SiO}_{3} 5 \mathrm{H}_{2} \mathrm{O}\right)$, de modo que a concentração final de Si na solução extratora fosse de $0,2 \mathrm{~mol} \mathrm{~L}^{-1}$. Para remover a sodalita formada $\left[\mathrm{Na}_{4} \mathrm{Al}_{3} \mathrm{Si}_{3} \mathrm{O}_{12}(\mathrm{OH})\right]$, foram efetuadas duas lavagens do resíduo com $90 \mathrm{~mL}$ de $\mathrm{HCl} \mathrm{0,5} \mathrm{mol} \mathrm{L}^{-1}$ (Norrish \& Taylor, 1961) com tempo de contato de $10 \mathrm{~min}$ para cada lavagem (Singh \& Gilkes, 1991). Após a lavagem para retirar o excesso de sal e secagem, o resíduo foi analisado por DRX (amostra não orientada) numa amplitude de 10 a $40^{\circ} 2 \theta$ e velocidade de $0,5^{\circ} 2 \theta / \mathrm{min}$. Utilizou-se $\mathrm{NaCl}$ como padrão interno para correção das distorções instrumentais (posição e largura a meia altura dos picos). A mistura (em torno de $50 \mathrm{mg} \mathrm{g}^{-1}$ ) foi feita triturando-se a amostra em almofariz na presença de $\mathrm{NaCl}$.

A relação $(\mathrm{R})$ entre $\mathrm{Gt}$ e $\mathrm{Hm}(\mathrm{R}=\mathrm{Gt} / \mathrm{Gt}+\mathrm{Hm})$ foi estimada com base na área dos picos dos minerais, segundo Torrent \& Cabedo (1986). Para quantificar a Hm e Gt na fração argila, promoveu-se a alocação do $\mathrm{Fe}_{2} \mathrm{O}_{3}$ obtido com DCB nestes minerais, considerando a fórmula química, relação Gt/ $(\mathrm{Gt}+\mathrm{Hm})$ e nível de substituição isomórfica de Fe por Al na estrutura (Netto, 1996, Melo et al., 2001b). A substituição isomórfica de Fe por $\mathrm{Al}$ (SI) na 
estrutura da Hm e Gt foi estimada pela posição dos picos destes minerais. A posição dos picos de $\mathrm{NaCl}$, em cada amostra, foi utilizada para corrigir os valores das posições dos picos da Hm e Gt. A SI na Gt foi calculada, segundo Schulze (1984), e, na Hm, segundo Schwertmann et al. (1979). O DMC da Hm e Gt foi calculado a partir da largura a meia altura (LMA) das reflexões (104) e (110) da Hm e (110), (130) e (111) da Gt, utilizando-se a equação de Scherrer (Klug \& Alexander, 1954). Para obtenção da largura a meia altura corrigida, utilizou-se a equação ajustada por Melo et al. (2001b) a partir dos dados apresentados por Klug \& Alexander (1954).

O DMC da Gb e da Ct foram calculadas a partir da LMA das reflexões (002), (110) e (001) em amostra desferrificada (tratadas com DCB), utilizando-se $\mathrm{NaCl}$ como padrão interno para obtenção do valor de $\beta$. De maneira análoga aos óxidos de Fe, o DMC foi obtido pela equação de Scherrer (Klug \& Alexander, 1954).

$O$ índice de cristalinidade da caulinita foi calculado a partir de DRX de amostras não orientadas, montadas em placas perfuradas, seguindo os procedimentos apresentados por Hughes \& Brown (1979).

\section{Análise termodiferencial (ATD) e análise termogravimétrica (ATG)}

As amostras da fração argila, tratadas com DCB, foram analisadas num derivatório SHIMADZU DTG-60, Simultâneus DTA-TG APPARATUS . A interpretação qualitativa foi feita pelas características dos picos endotérmicos e exotérmicos dos minerais (ATD), e a quantificação da Ct e Gb foi feita de acordo com a redução de massa da amostra, em decorrência da desidroxilação dos minerais (ATG) (Jackson, 1979).

\section{Análise estatística}

Os dados das determinações químicas (teores totais de $\mathrm{Si}$, Fe e $\mathrm{Al}$ ) e mineralógicas foram submetidos à análise de correlação simples (Pearson), utilizando-se o programa SPSS for Windows 10.0 .

\section{RESULTADOS E DISCUSSÃO}

\section{Granulometria dos solos}

Em geral, a fração argila é o principal constituinte dos horizontes Bw1 e Bw2 dos solos (Quadro 2). Embora existam pequenas diferenças nos materiais de origem (rocha do LBw com maior teor de Si Schneider, 1970) e no clima (IAPAR, 2000), os dois Latossolos apresentam textura muito argilosa, evidenciando a intensa alteração sofrida pelo material de origem.

Os teores de silte nos solos apresentaram-se elevados, com teor variando de 150 a $260 \mathrm{~g} \mathrm{~kg}^{-1}$ (Quadro 2). Esses valores foram superiores aos encontrado por Netto (1996) em Latossolos

Quadro 2. Análise granulométrica e teor de carbono orgânico (CO) de amostras dos solos

\begin{tabular}{|c|c|c|c|c|c|c|c|c|c|}
\hline \multirow{2}{*}{ Amostra } & \multirow{2}{*}{ Perfil/classe } & \multirow{2}{*}{ Horizonte } & \multirow{2}{*}{ CO } & \multicolumn{5}{|c|}{ Análise granuolométrica(1) } & \multirow{2}{*}{ Silte/argila } \\
\hline & & & & A & $\mathbf{S}$ & $\mathbf{A F}$ & $\mathbf{A G}$ & AT & \\
\hline & & & \multicolumn{6}{|c|}{$-\mathrm{g} \mathrm{kg}^{-1}$} & \\
\hline 1 & P1 LBw & Bw 1 & 13,0 & 770 & 190 & 20 & 20 & 40 & 0,24 \\
\hline 2 & P1 LBw & Bw2 & 3,3 & 760 & 190 & 20 & 30 & 50 & 0,25 \\
\hline 3 & P2 LBw & Bw1 & 13,6 & 760 & 190 & 20 & 30 & 50 & 0,25 \\
\hline 4 & P2 LBw & Bw2 & 5,1 & 770 & 150 & 40 & 40 & 80 & 0,19 \\
\hline 5 & P3 LBw & Bw1 & 13,6 & 780 & 180 & 20 & 20 & 40 & 0,23 \\
\hline 6 & P3 LBw & Bw2 & 4,5 & 760 & 200 & 10 & 30 & 40 & 0,26 \\
\hline 7 & $\mathrm{P} 4 \mathrm{LBw}$ & Bw1 & 19,0 & 760 & 210 & 30 & 30 & 60 & 0,28 \\
\hline 8 & $\mathrm{P} 4 \mathrm{LBw}$ & Bw2 & 8,8 & 680 & 260 & 40 & 20 & 60 & 0,38 \\
\hline 9 & P5 LVdf & Bw1 & 13,0 & 770 & 190 & 20 & 20 & 40 & 0,24 \\
\hline 10 & P5 LVdf & Bw2 & 5,1 & 760 & 190 & 30 & 20 & 50 & 0,25 \\
\hline 11 & P6 LVdf & Bw1 & 10,0 & 740 & 200 & 40 & 20 & 60 & 0,27 \\
\hline 12 & P6 LVdf & Bw2 & 4,5 & 750 & 190 & 30 & 30 & 60 & 0,25 \\
\hline 13 & P7 LVdf & Bw1 & 10,6 & 700 & 230 & 40 & 30 & 70 & 0,32 \\
\hline 14 & P7 LVdf & Bw2 & 7,5 & 680 & 200 & 70 & 50 & 120 & 0,29 \\
\hline 15 & P8 LVdf & Bw1 & 13,6 & 680 & 230 & 50 & 40 & 90 & 0,33 \\
\hline 16 & P8 LVdf & Bw2 & 8,8 & 680 & 250 & 40 & 60 & 100 & 0,38 \\
\hline
\end{tabular}

(1) $\mathrm{A}=$ argila, $\mathrm{S}=$ silte, $\mathrm{AF}=$ areia fina, $\mathrm{AG}=$ areia grossa e $\mathrm{AT}=$ areia total. 
originários do basalto da Região Sul do Brasil. Os maiores teores desta fração foram observados no horizonte $\mathrm{Bw} 2$ das partes mais baixas das toposseqüências (perfis 4 e 8), em razão, provavelmente, do menor estádio de intemperismo do solo localizado nesta posição do relevo. Outro fator que deve ser levado em consideração é a ineficiência do método de dispersão para solos com altos teores de óxidos de $\mathrm{Fe}$ e gibbsita, conforme observado por Melo et al. (2000). Embora não tenha sido analisada a constituição da fração silte, acreditase que seja constituída, em grande parte, por partículas de minerais da fração argila com alta estabilidade, sendo cimentadas pelos óxidos de Fe e Al. Mesmo com esta limitação metodológica, os valores da relação silte/argila foram baixos (Quadro 2), sendo inferiores ao limite de 0,6 determinado para Latossolo de textura argilosa (Embrapa, 1999).

\section{Teores totais de $\mathrm{Si}, \mathrm{Al}$ e Fe}

Os maiores teores de Si foram observados para as amostras do LBw (Quadro 3), evidenciando a característica básica intermediária do material de origem (Schneider, 1970). Verificou-se comportamento oposto para o $\mathrm{Fe}$, com valores superiores para o LVdf, refletindo a riqueza do material mais básico em minerais ferromagnesianos. Já os valores para as relações molares ki $\left(\mathrm{SiO}_{2} / \mathrm{Al}_{2} \mathrm{O}_{3}\right)$ e $\mathrm{kr}\left(\mathrm{SiO}_{2} / \mathrm{Al}_{2} \mathrm{O}_{3}+\right.$ $\mathrm{Fe}_{2} \mathrm{O}_{3}$ ) foram baixos, demonstrando avançado estádio de intemperismo desses solos. Valores semelhantes para estas relações foram reportados pela Embrapa (1984) em áreas localizadas próximas às analisadas neste estudo.

De acordo com o limite proposto pela Embrapa (1999), de maneira geral, o LBw pode ser classificado como caulinítico (ki $>0,75)$ e o LVdf como oxídico/ gibbsítico (ki e $\mathrm{kr}<0,75$ ) (Quadro 3). Os maiores valores de ki no $\mathrm{LBw}$ são atribuídos aos maiores teores de Si no material de origem e à menor ação da drenagem, representados pelo aumento na concentração do elemento nos horizontes mais profundos (com exceção do perfil 1) e nas áreas mais baixas da toposseqüência. Na descrição morfológica dos perfis, ficaram evidentes as reações de hidromorfismo no horizonte Bw2 do perfil 4 (Quadro 1). O enriquecimento de Si nos horizontes subsuperficiais também foi observado no trabalho de Clemente (2001).

\section{Extração de óxidos de Fe e Al de baixa cristalinidade}

A extração com Oxalato de Amônio Ácido (OAA), por ser um agente complexante, retira as formas de $\mathrm{Al}$ e $\mathrm{Fe}$ mal cristalizadas, principalmente a ferriidrita (Schwertmann \& Taylor, 1989). Este método também pode extrair aluminossilicatados amorfos (Jackson et al., 1986).

Para separar melhor os teores de Fe de baixa e alta cristalinidade, optou-se por apenas uma extração com OAA, conforme sugerido por outros autores (Ker, 1988; Melo, 1994). Os teores de $\mathrm{Fe}_{2} \mathrm{O}_{3}$ e $\mathrm{Al}_{2} \mathrm{O}_{3}$ menos cristalinos foram baixos em todas as

Quadro 3. Teores totais de óxidos de silício, alumínio e ferro da fração argila de amostras dos solos

\begin{tabular}{|c|c|c|c|c|c|c|c|}
\hline \multirow{2}{*}{ Amostra } & \multirow{2}{*}{ Perfil/classe } & \multirow{2}{*}{ Horizonte } & \multirow{2}{*}{$\mathrm{Fe}_{2} \mathrm{O}_{3}$} & \multirow{2}{*}{$\mathrm{Al}_{2} \mathrm{O}_{3}$} & \multirow{2}{*}{$\mathrm{SiO}_{2}$} & \multicolumn{2}{|c|}{ Relação molar ${ }^{(1)}$} \\
\hline & & & & & & $\mathbf{k i}$ & $\mathbf{k r}$ \\
\hline & & & 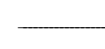 & $\mathrm{g} \mathrm{kg}^{-1}$ & - & & \\
\hline 1 & $\mathrm{P} 1 \mathrm{LBw}$ & Bw1 & 138 & 182 & 172 & 1,6 & 1,1 \\
\hline 2 & P1 LBw & Bw2 & 128 & 371 & 219 & 1,0 & 0,8 \\
\hline 3 & P2 LBw & Bw1 & 133 & 324 & 171 & 0,9 & 0,7 \\
\hline 4 & P2 LBw & $\mathrm{Bw} 2$ & 121 & 347 & 208 & 1,0 & 0,8 \\
\hline 5 & P3 LBw & Bw1 & 125 & 367 & 174 & 0,8 & 0,7 \\
\hline 6 & P3 LBw & Bw2 & 118 & 365 & 193 & 0,9 & 0,7 \\
\hline 7 & $\mathrm{P} 4 \mathrm{LBw}$ & Bw1 & 111 & 376 & 217 & 0,9 & 0,8 \\
\hline 8 & $\mathrm{P} 4 \mathrm{LBw}$ & Bw2 & 89 & 331 & 313 & 1,6 & 1,4 \\
\hline 9 & P5 LVdf & Bw1 & 223 & 429 & 143 & 0,6 & 0,4 \\
\hline 10 & P5 LVdf & Bw2 & 197 & 373 & 144 & 0,6 & 0,5 \\
\hline 11 & P6 LVdf & Bw1 & 207 & 368 & 143 & 0,6 & 0,5 \\
\hline 12 & P6 LVdf & Bw2 & 209 & 357 & 152 & 0,7 & 0,5 \\
\hline 13 & P7 LVdf & Bw1 & 218 & 388 & 142 & 0,6 & 0,5 \\
\hline 14 & P7 LVdf & Bw2 & 208 & 335 & 130 & 0,7 & 0,5 \\
\hline 15 & P8 LVdf & Bw1 & 221 & 343 & 152 & 0,8 & 0,5 \\
\hline 16 & P8 LVdf & Bw2 & 192 & 381 & 205 & 0,9 & 0,7 \\
\hline
\end{tabular}

(1) $\mathrm{ki}=1,7 \times \mathrm{SiO}_{2} / \mathrm{Al}_{2} \mathrm{O}_{3} ; \mathrm{kr}=1,7 \times \mathrm{SiO}_{2} /\left[\mathrm{Al}_{2} \mathrm{O}_{3}+\left(0,64 \times \mathrm{Fe}_{2} \mathrm{O}_{3}\right)\right]$. 
amostras, variando de 1,0 a $2,5 \mathrm{~g} \mathrm{~kg}^{-1}$ e de 3,5 a $5,1 \mathrm{~g} \mathrm{~kg}^{-1}$, respectivamente (Quadro 4). Os baixos teores de materiais amorfos podem ser atribuídos ao alto grau de intemperismo do solo, favorecendo a maior cristalinidade dos minerais. O material menos cristalino foi constituído principalmente por $\mathrm{Al}(62,9$ a 80,5\% do total de óxidos removidos - Quadro 4). Comportamento semelhante foi observado por Melo et al. (2001b) em solos originários de basalto. Os maiores teores de $\mathrm{Fe}_{2} \mathrm{O}_{3}$ e $\mathrm{Al}_{2} \mathrm{O}_{3}$ amorfos no horizonte $\mathrm{Bw} 1$ estão associados aos maiores teores de C orgânico neste horizonte (Quadro 2), uma vez que a fração húmica tem efeito inibidor na cristalização dos óxidos de Fe (Kämpf \& Schwertmann, 1983). Os perfis 3 e 4 (LBw) apresentaram maior teor total de $\mathrm{Fe}_{2} \mathrm{O}_{3}$ e $\mathrm{Al}_{2} \mathrm{O}_{3}$ de baixa cristalinidade no horizonte $\mathrm{Bw} 2$, provavelmente por localizarem-se nas partes mais baixas da toposseqúência, área com drenagem mais limitada (Quadro 1).

\section{Extração dos óxidos de ferro mais cristalinos (Hematita - Hm e Goethita - Gt)}

Após ter sido descontado o teor de $\mathrm{Fe}_{2} \mathrm{O}_{3}$-OAA (a extração dos óxidos de Fe mais cristalinos foi realizada em amostras da fração argila sem tratamento, utilizando o método do ditionito-citratobicarbonato - DCB), os teores de $\mathrm{Fe}_{2} \mathrm{O}_{3}$ mais cristalinos variaram de 98,6 a $280,0 \mathrm{~g} \mathrm{~kg}^{-1}$ (Quadro 5). Os maiores teores de $\mathrm{Fe}_{2} \mathrm{O}_{3}$-DCB foram obtidos para amostras do LVdf (amostras de 9 a 16), evidenciando, mais uma vez, a riqueza do material de origem em minerais ferromagnesianos.

$\mathrm{Na}$ toposseqüência do LBw, o menor teor de Fe cristalino foi obtido para a amostra 8 (Quadro 5), localizada na parte mais baixa da toposseqüência, onde há maior grau de umidade no solo. Isso evidencia a relação existente entre o regime de umidade do solo e processo de desferrificação. Verificou-se, em campo, a presença de mosqueado e coloração variegada (10YR 7/3, 7,5YR 5/6, 2,5YR 5/8) neste horizonte (Quadro 1).

Os teores de $\mathrm{Al}_{2} \mathrm{O}_{3}$ extraídos pelo DCB variaram de 26,4 a 64,0 $\mathrm{g} \mathrm{kg}^{-1}$ (Quadro 5). Esses valores foram altos, quando comparados aos encontrados por Ker (1988), em Latossolo Bruno, e por Melo et al. (2001b), em Latossolo Vermelho, ambos derivados de rochas eruptivas básicas. Os maiores teores de $\mathrm{Al}$ nos dois Latossolos localizaram-se nos horizontes Bw1, sendo atribuídos, provavelmente, ao maior nível de substituição isomórfica de Fe por Al na estrutura dos óxidos de Fe (Curi \& Franzmeier, 1984).

Os valores da relação Feo/Fed foram baixos (inferiores ou iguais a 0,019) (Quadro 5) em razão do predomínio de formas mais cristalinas. Valores semelhantes para essa relação foram encontrados por outros autores (Kämpf et al., 1988b; Fontes \& Weed, 1991; Santos, 1993; Melo, 1994; Melo et al., 2001b). No LBw, os maiores valores para a relação Feo/Fed foram observados nas amostras 7 e 8 (Quadro 5). No perfil 4, verificou-se maior teor de

Quadro 4. Teores de óxidos de ferro e alumínio extraídos pelo oxalato ácido de amônio (OAA) da fração argila de amostras dos solos

\begin{tabular}{|c|c|c|c|c|c|c|c|}
\hline \multirow{2}{*}{ Amostra } & \multirow{2}{*}{ Perfil/classe } & \multirow{2}{*}{ Horizonte } & \multirow{2}{*}{$\mathrm{Al}_{2} \mathrm{O}_{3}$} & \multirow{2}{*}{$\mathrm{Fe}_{2} \mathrm{O}_{3}$} & \multirow{2}{*}{ Total(1) } & \multicolumn{2}{|c|}{ Relação ao total(2) } \\
\hline & & & & & & $\mathrm{Fe}_{2} \mathrm{O}_{3}$ & $\mathrm{Al}_{2} \mathrm{O}_{3}$ \\
\hline & & & 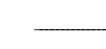 & $-\mathrm{g} \mathrm{kg}^{-1}$ & - & 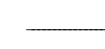 & - \\
\hline 1 & $\mathrm{P} 1 \mathrm{LBw}$ & Bw1 & 4,5 & 1,7 & 6,1 & 27,0 & 73,0 \\
\hline 2 & P1 LBw & Bw2 & 3,6 & 1,0 & 4,7 & 21,9 & 78,1 \\
\hline 3 & P2 LBw & Bw1 & 5,2 & 1,6 & 6,8 & 23,4 & 76,6 \\
\hline 4 & P2 LBw & $\mathrm{Bw} 2$ & 4,0 & 1,0 & 4,9 & 19,5 & 80,5 \\
\hline 5 & P3 LBw & Bw1 & 4,0 & 1,3 & 5,3 & 24,8 & 75,1 \\
\hline 6 & P3 LBw & Bw2 & 4,1 & 1,3 & 5,4 & 23,7 & 76,3 \\
\hline 7 & $\mathrm{P} 4 \mathrm{LBw}$ & Bw1 & 4,9 & 2,1 & 7,0 & 30,4 & 69,6 \\
\hline 8 & $\mathrm{P} 4 \mathrm{LBw}$ & Bw2 & 5,1 & 1,9 & 7,0 & 26,7 & 73,3 \\
\hline 9 & P5 LVdf & Bw1 & 4,5 & 2,0 & 6,4 & 30,5 & 69,4 \\
\hline 10 & P5 LVdf & Bw2 & 3,6 & 1,8 & 5,3 & 33,1 & 66,9 \\
\hline 11 & P6 LVdf & Bw1 & 4,0 & 1,8 & 5,9 & 30,8 & 69,2 \\
\hline 12 & P6 LVdf & Bw2 & 3,5 & 1,3 & 4,8 & 27,4 & 72,6 \\
\hline 13 & P7 LVdf & Bw1 & 4,7 & 2,4 & 7,2 & 34,0 & 66,0 \\
\hline 14 & P7 LVdf & Bw2 & 4,4 & 2,3 & 6,7 & 33,8 & 66,2 \\
\hline 15 & P8 LVdf & Bw1 & 4,4 & 2,5 & 7,0 & 36,7 & 63,3 \\
\hline 16 & P8 LVdf & Bw2 & 4,0 & 2,3 & 6,3 & 37,1 & 62,9 \\
\hline
\end{tabular}

(1) Total = soma dos óxidos $\left(\mathrm{Al}_{2} \mathrm{O}_{3}+\mathrm{Fe}_{2} \mathrm{O}_{3}\right)$. ${ }^{(2)}$ Participação de $\mathrm{Al}_{2} \mathrm{O}_{3}, \mathrm{Fe}_{2} \mathrm{O}_{3}$ e $\mathrm{SiO}_{2}$ em relação ao total (soma dos óxidos). 
Quadro 5. Teores de óxidos de ferro e alumínio extraídos pelo ditionito-citrato-bicarbonato (DCB) da fração argila de amostras dos solos

\begin{tabular}{|c|c|c|c|c|c|c|c|c|}
\hline \multirow{2}{*}{ Amostra } & \multirow{2}{*}{ Perfil/classe } & \multirow{2}{*}{ Horizonte } & \multirow{2}{*}{$\mathrm{Al}_{2} \mathrm{O}_{3}$} & \multirow{2}{*}{$\mathrm{Fe}_{2} \mathrm{O}_{3}$} & \multirow{2}{*}{ Total(1) } & \multicolumn{2}{|c|}{ Relação ao total(2) } & \multirow{2}{*}{ Feo/Fed ${ }^{(3)}$} \\
\hline & & & & & & $\mathrm{Al}_{2} \mathrm{O}_{3}$ & $\mathrm{Fe}_{2} \mathrm{O}_{3}$ & \\
\hline & & & $\underline{-}$ & $-\mathrm{g} \mathrm{kg}^{-1}$ & - & 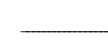 & - & \\
\hline 1 & P1 LBw & Bw 1 & 61,0 & 177,3 & 238,3 & 25,6 & 74,4 & 0,009 \\
\hline 2 & $\mathrm{P} 1 \mathrm{LBw}$ & $\mathrm{Bw} 2$ & 34,0 & 125,5 & 159,5 & 21,3 & 78,7 & 0,008 \\
\hline 3 & P2 LBw & Bw1 & 55,0 & 187,0 & 242,0 & 22,7 & 77,3 & 0,009 \\
\hline 4 & P2 LBw & $\mathrm{Bw} 2$ & 28,0 & 133,0 & 161,0 & 17,4 & 82,6 & 0,007 \\
\hline 5 & P3 LBw & Bw1 & 64,0 & 180,0 & 244,0 & 26,2 & 73,8 & 0,007 \\
\hline 6 & P3 LBw & Bw2 & 34,0 & 154,0 & 188,0 & 18,1 & 81,9 & 0,008 \\
\hline 7 & $\mathrm{P} 4 \mathrm{LBw}$ & $\mathrm{Bw} 1$ & 52,2 & 125,0 & 177,2 & 29,5 & 70,5 & 0,017 \\
\hline 8 & $\mathrm{P} 4 \mathrm{LBw}$ & Bw2 & 35,0 & 98,6 & 133,6 & 26,2 & 73,8 & 0,019 \\
\hline 9 & P5 LVdf & Bw1 & 50,0 & 280,0 & 330,0 & 15,1 & 84,8 & 0,008 \\
\hline 10 & P5 LVdf & Bw2 & 29,7 & 224,0 & 253,7 & 11,7 & 88,3 & 0,008 \\
\hline 11 & P6 LVdf & Bw1 & 42,0 & 193,0 & 235,0 & 17,9 & 82,1 & 0,009 \\
\hline 12 & P6 LVdf & $\mathrm{Bw} 2$ & 26,4 & 254,0 & 280,4 & 9,4 & 90,6 & 0,005 \\
\hline 13 & P7 LVdf & Bw1 & 42,0 & 227,0 & 269,0 & 15,6 & 84,4 & 0,011 \\
\hline 14 & P7 LVdf & Bw2 & 42,0 & 265,0 & 307,0 & 13,7 & 86,3 & 0,009 \\
\hline 15 & P8 LVdf & Bw 1 & 50,0 & 256,0 & 306,0 & 16,3 & 83,7 & 0,010 \\
\hline 16 & P8 LVdf & Bw2 & 47,0 & 236,0 & 283,0 & 16,6 & 83,4 & 0,008 \\
\hline
\end{tabular}

(1) Total = soma dos óxidos $\left(\mathrm{Al}_{2} \mathrm{O}_{3}+\mathrm{Fe}_{2} \mathrm{O}_{3}\right) .{ }^{(2)}$ Participação de $\mathrm{Al}_{2} \mathrm{O}_{3}, \mathrm{Fe}_{2} \mathrm{O}_{3}$ e $\mathrm{SiO}_{2}$ em relação ao total (soma dos óxidos). ${ }^{(3)}$ Relação entre $\mathrm{Fe}_{2} \mathrm{O}_{3} \mathrm{OAA} / \mathrm{Fe}_{2} \mathrm{O}_{3} \mathrm{DCB}$.

CO (Quadro 2) e adensamento dos horizontes, ou seja, menor aeração, a qual favorece as formas amorfas (Melo, 1994). Outro fator que provavelmente dificultou a cristalização dos óxidos de Fe no horizonte Bw1 e Bw2 do perfil 4 foi o maior teor de Si (Quadro 3).

\section{Composição mineralógica da fração argila}

A fração argila dos Latossolos é constituída principalmente por Ct, Gb, Hm e Gt (Quadro 6). As variações nos teores destes minerais são atribuídas às diferenças na composição química e mineralógica dos materiais de origem, clima das áreas de amostragem, condições de drenagem e remoção de Si do solo.

A soma dos minerais ficou relativamente próxima a $1.000 \mathrm{~g} \mathrm{~kg}^{-1}$. De acordo com os difratogramas de raios X da fração argila, identificaram-se outros minerais: quartzo (amostras 1 a 16), maghemita (amostras 9 a 16), clorita (amostra 9), vermiculita com hidróxi entre camadas (VHE) (amostras 1, 2, 3, $4,8,10,11,14$ e 15) e interestratificado VHE/clorita (amostras 5, 6, 7, 12 e 13). Os argilominerais 2:1 com $\mathrm{Al}$ interlamelar também foram encontrados em Latossolos Brunos do Sul do Brasil por outros autores (Lima, 1979; Palmieri, 1986; Ker, 1988). Antonello et al. (1984) atribuem a origem da VHE para alguns Latossolos do Paraná à intemperização dos feldspatos.
Segundo Schneider (1970), os plagioclásios, principal constituinte das rochas eruptivas básicas, são os mais importantes precursores da Ct. Os maiores teores de $\mathrm{Ct}$ foram obtidos no $\mathrm{LBw}$, com teores variando de 373,3 a 574,3 $\mathrm{g} \mathrm{kg}^{-1}$ (Quadro 6). Verificou-se um acréscimo nos teores de Ct com a profundidade do solo, provavelmente graças à maior concentração de Si no horizonte Bw2 (Quadro 3). A remoção de Si dos horizontes superiores pela ação da drenagem pode ter concentrado o elemento no horizonte Bw2, principalmente onde ocorrem camadas adensadas e maior proximidade do lençol freático. Aparentemente, também se verificou um fluxo lateral de $\mathrm{Si}$ no $\mathrm{LBw}$, com maior enriquecimento da $\mathrm{Ct}$ nos perfis inferiores da toposseqüência (amostras 7 e 8-Quadro 6). O maior teor de Si na solução do solo facilita a recombinação do elemento com o $\mathrm{Al}$ para formação da $\mathrm{Ct}(\mathrm{Hsu}$, 1989). Comportamento semelhante foi verificado por Curi \& Franzmeier (1984), trabalhando com uma toposseqüência de Latossolo Vermelho originado de basalto no Planalto Central do Brasil. No LVdf, os teores de $\mathrm{Ct}$ nas amostras ao longo da toposseqüência apresentaram-se semelhantes, provavelmente por causa da melhor condição de drenagem desta classe de solo em todas as posições da paisagem (Quadro 1).

Por outro lado, Os teores de Gb nos Latossolos variaram de 140,4 a $343,7 \mathrm{~g} \mathrm{~kg}^{-1}$, com maiores 
Quadro 6. Composição mineralógica da fração argila de amostras dos solos ${ }^{(1)}$

\begin{tabular}{|c|c|c|c|c|c|c|c|c|}
\hline Amostra & Perfil/classe & Horizonte & $\mathbf{C t}$ & $\mathbf{G b}$ & $\mathrm{Hm}$ & Gt & OAA & Total \\
\hline 1 & P1 LBw & Bw1 & 380 & 317 & 95 & 142 & 38 & 939 \\
\hline 2 & P1 LBw & Bw2 & 464 & 301 & 116 & 81 & 18 & 967 \\
\hline 3 & P2 LBw & Bw 1 & 386 & 306 & 40 & 181 & 48 & 919 \\
\hline 4 & P2 LBw & Bw2 & 522 & 258 & 86 & 105 & 18 & 966 \\
\hline 5 & P3 LBw & Bw1 & 373 & 315 & 114 & 101 & 42 & 908 \\
\hline 6 & P3 LBw & Bw2 & 462 & 326 & 124 & 61 & 21 & 979 \\
\hline 7 & P4 LBw & Bw 1 & 438 & 272 & 56 & 152 & 28 & 925 \\
\hline 8 & P4 LBw & Bw2 & 574 & 140 & 30 & 127 & 30 & 879 \\
\hline 9 & P5 LVdf & Bw1 & 294 & 322 & 309 & * & 38 & 932 \\
\hline 10 & P5 LVdf & $\mathrm{Bw} 2$ & 365 & 341 & 268 & $*$ & 23 & 979 \\
\hline 11 & P6 LVdf & Bw1 & 313 & 322 & 284 & $*$ & 25 & 924 \\
\hline 12 & P6 LVdf & Bw2 & 373 & 325 & 261 & $*$ & 35 & 964 \\
\hline 13 & P7 LVdf & Bw1 & 351 & 301 & 265 & 33 & 29 & 949 \\
\hline 14 & P7 LVdf & Bw2 & 335 & 323 & 240 & 60 & 35 & 965 \\
\hline 15 & P8 LVdf & Bw1 & 344 & 275 & 304 & 9 & 23 & 939 \\
\hline 16 & P8 LVdf & Bw2 & 374 & 314 & 220 & 45 & 42 & 959 \\
\hline
\end{tabular}

(1) Teores de Ct (Caulinita) e Gb (Gibbsita) determinados com base na perda de massa de amostra de argila por meio de análise termo gravimétrica (Jackson, 1979). Hm (Hematita) e Gt (Goethita) quantificadas com base no teor de Fe $\mathrm{O}_{3}$ ditionito-citratobicarbonato e características obtidas por difratometria de raios X (Netto, 1996; Melo et al., 2001b). OAA = Teor de minerais de baixa cristalinidade obtido pela remoção de material pela extração com oxalato de amônio ácido [(peso inicial da amostra- peso final da amostra)/peso inicial da amostra] ${ }^{*} 1000 . *$ Mineral ausente.

valores no LVdf (Quadro 6). A formação da Gb é rápida, quando ocorre a separação do Si ligado ao $\mathrm{Al}$ e, ou, remoção do Si pela ação da água (Hsu, 1989).

O principal fator para determinar o predomínio da Hm na fração argila é o alto teor de minerais ferromagnesianos no material de origem (Almeida, 1979), o que justifica o maior teor do mineral no LVdf (amostra 9 a 16). Já no LBw, de maneira geral, verificou-se o predomínio de Gt, principalmente no horizonte Bw1, favorecido pelo maior teor de matéria orgânica (Quadro 2) e menor temperatura média anual (IAPAR, 2000). O maior teor de Gt do horizonte Bw2 deste solo foi observado na amostra 8 (Quadro 6), localizada na parte mais baixa da toposseqüência, onde o teor de água foi maior (Quadro 1), provocando a remoção parcial do $\mathrm{Fe}$ (menor $\mathrm{Fe}_{2} \mathrm{O}_{3}$-DCB - Quadro 5). Estas condições são mais favoráveis à formação da Gt (Schwertmann, 1988).

\section{Características cristalográficas dos óxidos de ferro (Hm e Gt)}

Com base nas características dos óxidos de Fe, obtidas a partir dos difratogramas de raios $\mathrm{X}$ (Quadro 7), verificou-se o efeito do material de origem na relação $\mathrm{Gt} /(\mathrm{Gt}+\mathrm{Hm})$ da fração argila, uma vez que as correlações entre $\mathrm{Fe}_{2} \mathrm{O}_{3}$-total e $\mathrm{Fe}_{2} \mathrm{O}_{3}$-DCB com esta relação foram negativas e significativas a $0,05\left(\mathrm{r}=-0,89^{* *}\right.$ e $-0,78^{* *}$, respectivamente).

A distância interplanar (d) dos óxidos de $\mathrm{Fe}$, em várias direções, foi corrigida utilizando o $\mathrm{NaCl}$ como padrão interno (Quadro 7). A maior dificuldade para medir a posição exata dos picos foi para a Gt (130) e para a Hm (104), dada a proximidade dessas reflexões. O diâmetro médio do cristal (DMC), de um mesmo mineral, fornece informações sobre o hábito de crescimento dos cristais (Netto, 1996). No presente trabalho, a Gt das amostras 13,14,15 e 16, do LVdf, e 6 do LBw, apresentaram maiores valores de DMC na direção (111) que na direção (110), o que pode estar evidenciando formato acicular do mineral, conforme observações de Amarasiriwardena et al., (1988). Por sua vez, as amostras 3, 4 e 7 do LBw comportaram-se opostamente, ou seja, o DMC (111) foi menor que o DMC (110). Resultados semelhantes foram obtidos por Fontes \& Weed (1991) e Netto (1996). Já a Gt das amostras 1, 2, 5 e 8 do LBw demonstrou proximidade de valores entre o DMC (111) e DMC (110), indicando formato isodimencional, bastante comum para o mineral em solos dos trópicos úmidos (Schwertmann \& Kämpf, 1985). Já a Hm apresentou valores de DMC na direção (110) superiores aos do DMC (104), revelando a forma de placa, normalmente encontrada nas hematitas sintéticas (Schwertmann et al., 1979) e Hm de solo (Fontes \& Weed, 1991). Na maioria das amostras, 
a $\mathrm{Hm}$ apresentou maior tamanho que a Gt, principalmente na direção (110), concordando com os resultados obtidos por outros autores (Curi \& Franzmeier, 1984; Melo et al., 2001b).

Os valores de substituição isomórfica (SI) de Fe por Al na estrutura da Gt variaram de 140 a $310 \mathrm{mmol} \mathrm{mol}^{-1}$, com média de $225 \mathrm{mmol} \mathrm{mol}^{-1}$, enquanto, para a $\mathrm{Hm}$, os valores ficaram entre $27 \mathrm{e}$ $150 \mathrm{mmol} \mathrm{mol}^{-1}$, com média de $88 \mathrm{mmol} \mathrm{mol}^{-1}$ (Quadro 7). Embora este fenômeno tenha maior importância na Gt, não se observou correlação significativa entre teor de Al extraído pelo DCB e SI no mineral $(r=0,14)$.

A presença do $\mathrm{Al}$ na estrutura da Gt normalmente diminui o tamanho e o grau de cristalinidade do mineral, que podem ser indicados pelos valores de DMC e LMH. Menores valores de LMH (111) estão associados à Gt de maior grau de cristalinidade, com menor presença de $\mathrm{Al}$ na estrutura (Fitzpatrick \& Schwertmann, 1982). Contudo, não houve correlação entre DMC (111) e LMH (111) com SI na $\mathrm{Gt}(\mathrm{r}=-0,27$ e 0,20, respectivamente). O maior grau de cristalinidade da Gt (menor LMH) foi observado no LVdf (amostras 13 a 16) (Quadro 7), possivelmente influenciado pelo maior teor de Fe total nestes horizontes ( $r$ entre Fe total e LMH (111) para as amostras de 13 a $\left.16=-0,72^{* * *}\right)$.

De maneira geral, não houve variação consistente nos valores dos atributos cristalográficos (d, DMC,
LMH e SI) da Hm e Gt, considerando a profundidade do solo e a posição do perfil na toposseqüência (Quadros 1 e 7).

\section{Características cristalográficas da caulinita e gibbsita}

As distorções do aparelho de DRX sobre as características cristalográficas da $\mathrm{Ct}$ e $\mathrm{Gb}$ foram corrigidas com o uso de $\mathrm{NaCl}$ como padrão interno. Os valores de d(001) para a Ct variaram de 0,714 a $0,729 \mathrm{~nm}$ (Quadro 8), com média de 0,721 nm, sendo semelhantes entre os dois Latossolos. Normalmente, as variações nos valores de d(001) são promovidas pela entrada de $\mathrm{Fe}$ e outros elementos na estrutura e estão relacionadas com o tamanho da $\mathrm{Ct}$, onde partículas pequenas tendem a apresentar maiores valores de d(001) (Koppi \& Skjemstad, 1981). Contudo, neste trabalho, o coeficiente de correlação entre d(001) e DMC (001) foi baixo e não-significativo $(r=0,29)$. Tettenhorst \& Corbató (1986) também não observaram associação entre tamanho de partícula e valor de $\mathrm{d}(001)$.

Os valores de DMC (001) da Ct variaram de 12,1 a 19,8 nm (Quadro 8), sendo semelhantes aos valores dos óxidos de Fe (Quadro 7), comportamento também observado por Netto (1996). Os valores de DMC (001) da Ct ficaram próximos aos obtidos por Melo et al. (2001a) em Latossolo Vermelho originado de basalto, em região de clima tropical úmido. O DMC (001) e o

Quadro 7. Largura a meia altura (LMH) e distância interplanar (d) corrigidas, diâmetro médio do cristal (DMC), substituição isomórfica de ferro por alumínio (SI) na goethita (Gt) e hematita (Hm) e relação $\mathrm{Gt} /(\mathrm{Gt}+\mathrm{Hm})$ para a fração argila de amostras dos solos ${ }^{(1)}$

\begin{tabular}{|c|c|c|c|c|c|c|c|c|c|c|c|c|c|}
\hline \multirow[b]{2}{*}{ Perfil/classe Hor. } & \multicolumn{5}{|c|}{ d-corrigido } & \multirow[b]{2}{*}{$\mathrm{Gt} /(\mathrm{Gt}+\mathrm{Hm})$} & \multicolumn{5}{|c|}{ DMC } & \multirow{2}{*}{$\begin{array}{c}\text { LMG } \\
\text { Gt } \\
\text { (111) }\end{array}$} & SI \\
\hline & $\begin{array}{c}\mathrm{Gt} \\
(110)\end{array}$ & $\begin{array}{c}\text { Gt } \\
(111)\end{array}$ & $\begin{array}{c}\mathrm{Gt} \\
(130)\end{array}$ & $\underset{(\mathbf{1 0 4})}{\mathrm{Hm}}$ & $\underset{\text { (110) }}{\mathrm{Hm}}$ & & $\begin{array}{c}\mathrm{Gt} \\
(110)\end{array}$ & $\begin{array}{c}\text { Gt } \\
\text { (111) }\end{array}$ & $\begin{array}{c}\mathrm{Gt} \\
(130)\end{array}$ & $\underset{\mathbf{( 1 0 4 )}}{\mathrm{Hm}}$ & $\underset{(110)}{\mathrm{Hm}}$ & & Gt $\mathrm{Hm}$ \\
\hline
\end{tabular}

\begin{tabular}{|c|c|c|c|c|c|c|c|c|c|c|c|c|c|c|c|c|}
\hline \multirow[b]{2}{*}{1} & \multirow[b]{2}{*}{ P1 LBw } & \multirow[b]{2}{*}{ Bw1 } & \multicolumn{5}{|c|}{$\longrightarrow \mathrm{nm}$} & \multirow[b]{2}{*}{0,60} & \multicolumn{5}{|c|}{$\mathrm{nm}$} & \multirow{2}{*}{$\begin{array}{l}\circ 2 \theta \\
0,79\end{array}$} & \multicolumn{2}{|c|}{$\mathrm{mmol} \mathrm{mol}^{-1}$} \\
\hline & & & 0,416 & 0,242 & 0,266 & 0,269 & 0,250 & & 14,0 & 12,3 & 23,7 & 17,2 & 17,9 & & 310 & 138 \\
\hline 2 & P1 LBw & $\mathrm{Bw} 2$ & 0,416 & 0,242 & 0,266 & 0,269 & 0,251 & 0,41 & 15,3 & 17,8 & 23,3 & 17,9 & 23,6 & 0,60 & 254 & 113 \\
\hline 3 & P2 LBw & Bw1 & 0,410 & 0,241 & nd & 0,268 & 0,251 & 0,82 & 15,1 & 8,6 & nd & 19,8 & 23,2 & 1,1 & 197 & 39 \\
\hline 4 & P2 LBw & Bw2 & 0,417 & 0,242 & nd & 0,268 & 0,251 & 0,55 & 19,9 & 15,9 & nd & 28,9 & 39,9 & 0,7 & 260 & 100 \\
\hline 5 & P3 LBw & Bw1 & 0,417 & 0,243 & 0,265 & 0,269 & 0,250 & 0,47 & 13,6 & 10,3 & 63,3 & 14,5 & 14,3 & 0,9 & 197 & 150 \\
\hline 6 & P3 LBw & Bw2 & 0,417 & 0,245 & 0,267 & 0,269 & 0,251 & 0,33 & 14,3 & 30,5 & 26,7 & 12,3 & 14,9 & 0,45 & 140 & 76 \\
\hline 7 & P4 LBw & Bw1 & 0,416 & 0,249 & 0,269 & 0,270 & 0,250 & 0,73 & 17,5 & 11,3 & 18,9 & 22,5 & 29,1 & 0,85 & 240 & 150 \\
\hline 8 & $\mathrm{P} 4 \mathrm{LBw}$ & Bw2 & 0,416 & 0,243 & 0,267 & 0,269 & 0,251 & 0,81 & 9,1 & 10,4 & 34,6 & 25,0 & 25,0 & 0,90 & 254 & 27 \\
\hline 9 & P5 LVdf & Bw1 & * & * & * & 0,269 & 0,251 & 0,00 & * & * & * & 16,4 & 19,8 & * & * & 138 \\
\hline 10 & P5 LVdf & Bw2 & * & * & * & 0,269 & 0,250 & 0,00 & * & * & * & 20,9 & 23,6 & * & * & 150 \\
\hline 11 & P6 LVdf & Bw1 & * & * & * & 0,269 & 0,251 & 0,00 & * & * & * & 18,5 & 23,3 & * & * & 101 \\
\hline 12 & P6 LVdf & Bw2 & * & * & * & 0,268 & 0,251 & 0,00 & * & * & * & 17,4 & 22,6 & * & * & 113 \\
\hline 13 & P7 LVdf & Bw1 & 0,416 & 0,241 & nd & 0,269 & 0,250 & 0,11 & 17,1 & 30,4 & nd & 23,3 & 24,5 & 0,43 & 310 & 138 \\
\hline 14 & P7 LVdf & Bw2 & 0,414 & 0,243 & nd & 0,269 & 0,251 & 0,22 & 17,1 & 23,4 & nd & 17,6 & 26,7 & 0,50 & 140 & 88 \\
\hline 15 & P8 LVdf & Bw1 & 0,415 & 0,243 & nd & 0,268 & 0,250 & 0,03 & 16,9 & 66,3 & nd & 14,1 & 24,7 & 0,30 & 197 & 125 \\
\hline 16 & P8 LVdf & Bw2 & 0,417 & 0,244 & nd & 0,269 & 0,250 & 0,17 & 16,7 & 44,9 & nd & 17,4 & 27,0 & 0,35 & 197 & 113 \\
\hline
\end{tabular}

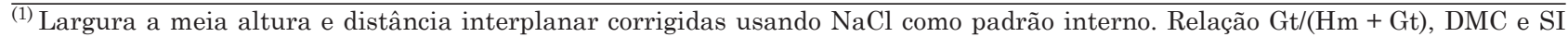
calculados com base nos difratogramas de raios X. * não detectado e nd não determinado pela baixa intensidade da reflexão. 
Quadro 8. Características com base nos difratogramas de raios X e temperatura de desidroxilação da caulinita da fração argila de amostras dos $\operatorname{solos}^{(1)}$

\begin{tabular}{|c|c|c|c|c|c|c|c|c|c|}
\hline Amostra & Perfil/classe & Horizonte & $d(001)$ & $d(002)$ & LMH (001) & DMC (001) & NMC (001) & ICHB & TD \\
\hline & & & \multicolumn{2}{|c|}{$\longrightarrow \mathrm{nm}$} & $\circ 2 \theta$ & $\mathrm{nm}$ & & & ${ }^{\circ} \mathrm{C}$ \\
\hline 1 & P1 LBw & $\mathrm{Bw} 1$ & 0,725 & 0,357 & 0,70 & 14,2 & 19,5 & 9,0 & 500 \\
\hline 2 & P1 LBw & $\mathrm{Bw} 2$ & 0,724 & 0,356 & 0,55 & 19,8 & 27,4 & 9,1 & 507 \\
\hline 3 & P2 LBw & $\mathrm{Bw} 1$ & 0,719 & 0,357 & 0,85 & 12,1 & 16,8 & 9,9 & 495 \\
\hline 4 & P2 LBw & $\mathrm{Bw} 2$ & 0,721 & 0,357 & 0,64 & 15,8 & 21,9 & 9,9 & 511 \\
\hline 5 & P3 LBw & $\mathrm{Bw} 1$ & 0,721 & 0,352 & 0,60 & 16,9 & 23,5 & 8,3 & 500 \\
\hline 6 & P3 LBw & $\mathrm{Bw} 2$ & 0,714 & 0,358 & 0,70 & 14,2 & 19,8 & 8,5 & 500 \\
\hline 7 & P4 LBw & $\mathrm{Bw} 1$ & 0,724 & 0,357 & 0,70 & 13,7 & 18,9 & 8,8 & 499 \\
\hline 8 & P4 LBw & $\mathrm{Bw} 2$ & 0,728 & 0,358 & 0,70 & 13,9 & 19,1 & 8,2 & 506 \\
\hline 9 & P5 LVdf & $\mathrm{Bw} 1$ & 0,727 & 0,353 & 0,70 & 13,7 & 18,8 & 6,5 & 500 \\
\hline 10 & P5 LVdf & Bw2 & 0,716 & 0,356 & 0,65 & 15,1 & 21,1 & 6,9 & 490 \\
\hline 11 & P6 LVdf & Bw1 & 0,724 & 0,356 & 0,60 & 19,2 & 26,5 & 7,1 & 500 \\
\hline 12 & P6 LVdf & Bw2 & 0,724 & 0,356 & 0,65 & 16,1 & 22,2 & 7,2 & 499 \\
\hline 13 & P7 LVdf & Bw1 & 0,723 & 0,357 & 0,75 & 12,8 & 17,7 & 7,2 & 495 \\
\hline 14 & P7 LVdf & $\mathrm{Bw} 2$ & 0,729 & 0,356 & 0,60 & 14,6 & 20,0 & 5,7 & 490 \\
\hline 15 & P8 LVdf & Bw1 & 0,728 & 0,355 & 0,56 & 19,8 & 27,1 & 7,7 & 500 \\
\hline 16 & P8 LVdf & $\mathrm{Bw} 2$ & 0,716 & 0,353 & 0,80 & 12,5 & 17,4 & 7,4 & 504 \\
\hline
\end{tabular}

(1) d(001), d(002) e LMH (001) = distância interplanar e largura a meia altura corrigidas pelo uso do NaCl como padrão interno, DMC $(001)$ = diâmetro médio do cristal, NMC = número médio de camadas [DMC(001)/d(001)], ICHB = índice de cristalinidade de Hughes e Brown (Hughes \& Brown, 1979), TD = temperatura de desidroxilação determinada pela análise térmica diferencial.

número médio de camadas (NMC) da Ct apresentaram comportamento semelhante nos dois Latossolos (Quadro 8). Os resultados apresentados por Melo et al. (2001a) demonstraram que o crescimento da Ct é favorecido pela menor interferência de partículas orgânicas. No presente estudo, não houve correlação entre teor de $\mathrm{CO}$ e valores de $\mathrm{DMC}(\mathrm{r}=0,12)$.

$\mathrm{O}$ índice de cristalinidade de Hughes \& Brown (ICHB) (Hughes \& Brown, 1979) da Ct dos Latossolos apresentou valores entre 5,7 e 9,9 (Quadro 8). Esses valores de ICHB são baixos em relação a Ct de clima temperado e Ct padrão (Singh \& Gilkes, 1992). Melo et al. (2001a) obtiveram valores para o ICHB da Ct de Latossolos no Brasil originário de basalto entre 11,4 e 12,2. A baixa cristalinidade da Ct é típica para minerais com alto grau de desordem estrutural (Hughes \& Brown, 1979), provocadas por defeitos no empilhamento das camadas do mineral (crescimento na direção Z) e interestratificação com outros minerais (Plançon \& Zacarie, 1990). A redução na cristalinidade e o aumento da área superficial da Ct também podem ser decorrentes da presença de Fe na estrutura do mineral (Mestdagh et al., 1980). Dentre os perfis estudados, os menores índices de cristalinidade foram verificados nas amostras de 9 a 16 (Quadro 8), pertencentes ao LVdf, os quais apresentaram maiores teores de Fe total (Quadro 3). O tamanho das partículas de Ct (DMC) não apresentou correlação com ICHB. Quanto maior o grau de cristalinidade, maior a temperatura necessária para desidroxilação do mineral $\left(r=0,79^{* *}\right)$. Desta forma, as amostras pertencentes ao LVdf apresentaram as menores temperaturas de desidroxilação (TD) (Quadro 8).

Os valores de DMC (002) da Gb oscilaram de 51,8 a 115,3 nm, com valor médio de 83,6 nm (Quadro 9), indicando maior tamanho do mineral em relação aos óxidos de Fe (Quadro 7). Outros autores, utilizando a mesma técnica de determinação do DMC, encontraram resultados semelhantes (Netto, 1996; Melo et al., 2001a). As amostras 7 e 8 (LBw) apresentaram os menores valores de DMC para a Gb (Quadro 9) e maior teor de Si total (Quadro 3).

O DMC (110) da Gb apresentou correlação negativa com teor de Si total e relações ki e kr ( $r=$ $-0,63^{* *},-0,66^{* *}$ e $-0,71^{* *}$, respectivamente). Dessa forma, solos com maior grau de intemperismo apresentaram maiores cristais de Gb. A formação e o crescimento dos cristais de Gb são favorecidos pela baixa concentração de Si no solo (Hsu, 1989). Com relação à forma das partículas da Gb, Mesquita Filho \& Torrent (1993) encontraram formato subarredondado com diâmetro de aproximadamente $75 \mathrm{~nm}$ em Gb de solos do Cerrado brasileiro. Netto (1996) dividiu o diâmetro (DMC 110) pela altura (DMC 002) e obteve valor aproximado de 0,7 , evidenciando o formato prismático para o mineral. No entanto, Melo et al. (2001a), utilizando técnicas de difração de raios X e microscopia eletrônica, encontraram formato de pequenas placas retangulares para $\mathrm{Gb}$ 
de diferentes classes de solo do Brasil. A relação DMC (110)/DMC (002) (Quadro 9) mostra valores iguais ou próximos a 0,2 , o que leva ao igual formato de placas para Gb. De forma similar ao observado para a $\mathrm{Ct}$, as maiores partículas da Gb necessitaram de maior temperatura para serem desidroxiladas $(\mathrm{r}$ entre DMC e TD $=0,70^{* *}$ ). Melo et al. (2001b) observaram relação entre os valores de TD e teores de $\mathrm{Gb}$, a qual não foi observada neste trabalho.

\section{CONCLUSÕES}

1. O teor de Si nas rochas basálticas e a posição dos perfis na paisagem foram importantes na definição da mineralogia da fração argila, com predomínio de óxidos de $\mathrm{Al}$ e $\mathrm{Fe}$ (gibbsita e hematita) no Latossolo Vermelho distroférrico (LVdf). Verificaram-se também maiores teores de $\mathrm{SiO}_{2}$ total e de caulinita (Ct) nos horizontes mais profundos (Bw2) e nos perfis mais baixos na toposseqüência do Latossolo Bruno ácrico (LBw).

2. Em virtude do elevado grau de intemperismo dos solos, os teores de óxidos de $\mathrm{Fe}$ e $\mathrm{Al}$ de baixa cristalinidade foram inexpressivos. A única exceção foi para o perfil 4 do $\mathrm{LBw}$ (ponto mais baixo da toposseqüência), em que a maior presença de água, associada à drenagem limitada, favoreceu os maiores teores destes minerais e os menores teores de $\mathrm{Fe}_{2} \mathrm{O}_{3}$ obtido com a extração com ditionito-citratobicarbonato (óxidos de Fe mais cristalinos).

3. De maneira geral, não houve variação consistente nos valores dos atributos cristalográficos da hematita e goethita de acordo com a profundidade do solo e posição do perfil na toposseqüência. Os menores índices de cristalinidade da $\mathrm{Ct}$ foram verificados nas amostras do LVdf, associados ao maior teor de $\mathrm{Fe}$ total no solo $\left(\mathrm{r}=0,79^{* *}\right)$. Os maiores teores de Si total no perfil 4 do LBw também dificultaram a formação e o crescimento da gibbsita [menor valor do diâmetro médio do cristal no domínio (110)].

\section{LITERATURA CITADA}

ALMEIDA, J.R. Cronocromoseqüência de solos originários de rochas pelíticas do grupo Bambuí. Viçosa, MG, Universidade Federal de Viçosa, 1979. 150p. (Tese de Mestrado)

AMARASIRIWARDENA, D.D.; BOWEN, L.H. \& WEED, S.B. Characterization and quantification of aluminumsubstituted hematite-goethite mixtures by x-ray diffraction and infrared and mossliauer spectroscopy. Soil Sci. Soc. Am. J., 52:1179-1186, 1988.

ANTONELLO, L.L. Gênese de uma seqüência de solos de rochas alcalinas do maciço do Itatiaia, RJ; Mineralogia geoquímica e micromorfologia. Rio de Janeiro, Universidade Federal de Rio de Janeiro, 1983. 178p. (Tese de Doutorado)

Quadro 9. Características com base nos difratogramas de raios X e temperatura de desidroxilação da gibbsita da fração argila de amostras dos $\operatorname{solos}^{(1)}$

Amostra Perfil/classe Horizonte d(002) d(110) LMH (002) LMH (110) DMC (002) DMC (110) R1 TD

\begin{tabular}{|c|c|c|c|c|c|c|c|c|c|c|}
\hline \multirow[b]{2}{*}{1} & \multirow[b]{2}{*}{ P1 LBw } & \multirow[b]{2}{*}{ Bw1 } & \multicolumn{2}{|c|}{$-\mathrm{nm}-$} & \multicolumn{2}{|c|}{${ }^{\circ} 2 \theta$} & \multicolumn{2}{|c|}{$\mathrm{nm}$} & \multicolumn{2}{|r|}{${ }^{\circ} \mathrm{C}$} \\
\hline & & & 0,485 & 0,436 & 0,335 & 0,778 & 58,7 & 12,4 & 0,20 & 272 \\
\hline 2 & P1 LBw & Bw2 & 0,483 & 0,438 & 0,283 & 0,535 & 92,9 & 20,9 & 0,22 & 280 \\
\hline 3 & P2 LBw & Bw1 & 0,486 & 0,436 & 0,394 & 0,740 & 65,2 & 15,1 & 0,23 & 272 \\
\hline 4 & P2 LBw & Bw2 & 0,484 & 0,438 & 0,288 & 0,599 & 86,9 & 17,6 & 0,20 & 281 \\
\hline 5 & P3 LBw & Bw1 & 0,485 & 0,438 & 0,320 & 0,698 & 56,2 & 13,9 & 0,24 & 272 \\
\hline 6 & P3 LBw & Bw2 & 0,485 & 0,437 & 0,297 & 0,592 & 88,0 & 18,3 & 0,20 & 283 \\
\hline 7 & $\mathrm{P} 4 \mathrm{LBw}$ & Bw1 & 0,484 & 0,437 & 0,320 & 0,850 & 56,2 & 10,8 & 0,19 & 267 \\
\hline 8 & $\mathrm{P} 4 \mathrm{LBw}$ & Bw2 & 0,484 & 0,438 & 0,340 & 1,180 & 51,8 & 7,3 & 0,14 & 268 \\
\hline 9 & P5 LVdf & Bw1 & 0,485 & 0,436 & 0,299 & 0,600 & 68,2 & 17,1 & 0,25 & 280 \\
\hline 10 & P5 LVdf & Bw2 & 0,485 & 0,437 & 0,323 & 0,580 & 54,8 & 18,0 & 0,33 & 280 \\
\hline 11 & P6 LVdf & Bw1 & 0,484 & 0,436 & 0,319 & 0,548 & 98,5 & 22,7 & 0,23 & 273 \\
\hline 12 & P6 LVdf & Bw2 & 0,484 & 0,437 & 0,289 & 0,503 & 115,3 & 24,8 & 0,21 & 286 \\
\hline 13 & P7 LVdf & Bw1 & 0,484 & 0,437 & 0,296 & 0,698 & 83,6 & 14,3 & 0,17 & 273 \\
\hline 14 & P7 LVdf & Bw2 & 0,485 & 0,436 & 0,320 & 0,499 & 59,7 & 23,2 & 0,38 & 274 \\
\hline 15 & P8 LVdf & Bw1 & 0,485 & 0,438 & 0,298 & 0,558 & 86,9 & 20,1 & 0,23 & 277 \\
\hline 16 & P8 LVdf & Bw2 & 0,485 & 0,438 & 0,310 & 0,545 & 57,1 & 19,3 & 0,33 & 273 \\
\hline
\end{tabular}

(1) d(002), d(110) e LMH (002) e LMH (110) = distância interplanar e largura a meia altura corrigidas pelo uso do NaCl como padrão interno. DMC (002) e DMC (110) = diâmetro médio do cristal. R1 relação com base nos valores de DMC = DMC(110)/DMC(002). TD = temperatura de desidroxilação determinada pela análise térmica diferencial. 
ANTONELLO, L.L.; MOLLER, R.M.F.; MONIZ, A.C. \& DURIEZ, M.A. Mineralogía de argilas de horizontes B de Latosols do Sudeste e Sul do Brasil. In: EMPRESA BRASILEIRA DE PESQUISA AGROPECUÁRIA SERVIÇO NACIONAL DE LEVANTAMENTO E CONSERVAÇÃO DE SOLOS. Investigações coligadas em variedades selecionadas de Latossolos do Brasil Sudeste e Sul. Rio de Janeiro, 1984. p.32-67.

BESOAIN, E. Mineralogia de arcillas de suelos. San José, Instituto Interamericanos de Cooperativas para la Agricultura, 1985. 1205p.

BIGARELLA, J.J.; BECKER, R.D. \& SANTOS, G.F. Estrutura e origem das paisagens tropicais e subtropicais. Fundamentos geológico-geográfficos alteração química e física das rochas. In: BECKER, R.D., ed. Relevo cárstico e dômico. Florianópolis, Universidade Federal de Santa Catarina, 1994. p.31-76.

CARVALHO, W.A. Relações entre relevo e solos da bacia do Rio Capivara - município de Botucatu, SP. Botucatu, Universidade Estadual de São Paulo, 1981. 193p. (Tese de Livre Docência)

CLEMENTE, C.A. Intemperismo de riólitos e riodacitos da formação Serra Geral (jurássico-cretáceo, das regiões sul e sudeste do Brasil. Piracicaba, Escola Superior de Agricultura Luiz de Queiroz, 2001. 216p. (Tese de Livre Docência)

CURI, N. \& FRANZMEIER, D.P. Toposequence of Oxisols from the Central Plateau of Brazil. Soil Sci. Soc. Am. J., 48:341346, 1984.

EMPRESA BRASILEIRA DE PESQUISA AGROPECUÁRIA EMBRAPA. Levantamento de reconhecimento dos solos do Estado do Paraná Tomo I. Rio de Janeiro, Centro Nacional de Pesquisa de Solos, Londrina, 1984. Tomo I. 413p.

EMPRESA BRASILEIRA DE PESQUISA AGROPECUÁRIA . EMBRAPA. Manual de métodos de análise de solo. $2^{\mathrm{a}}$ ed. Rio de Janeiro, Centro Nacional de Pesquisa de Solos, 1997. $212 \mathrm{p}$.

EMPRESA BRASILEIRA DE PESQUISA AGROPECUÁRIA EMBRAPA. Centro Nacional de Pesquisas de Solos. Rio de Janeiro. Sistema Brasileiro de classificação de solos. Brasília, Serviço de Produção de Informação, 1999. 412p.

FITZPATRICK, R.W. \& SCHWERTMANN, U. Al-substituted goethite - An indicator of pedogenic and other weathering environments in South Africa. Geoderma, 27:335-347, 1982.

FONTES, M.P.F. \& WEED, S.B. Iron oxides in selected Brazilian Oxisols. I. Mineralogy. Soil Sci. Soc. Am. J., 55:1143-1149, 1991.

GEE, G.W. \& BAUDER, J.W. Particle-size analysis. In: KLUTE, A., ed. Methods of soil analysis. 2.ed. Madison, American Society of Agronomy, 1986. p.383-412.

HSU, P.H. Aluminiun oxides and oxyhydroxides. In: DIXON, J.B. \& WEED, S.B., eds. Minerals in soil environments. 2.ed. Madison, Soil Science Society of America, 1989. p.331378 .

HUGHES, J.C. \& BROWN, G. A crystallinity index for soil kaolinite and its relation to parent rock, climate and soil maturity. J. Soil Sci., 30:557-563, 1979.
INSTITUTO DE PESQUISA AGROPECUÁRIA DO PARANAIAPAR. Cartas climáticas do Paraná. Londrina, v.1.0, 2000. 1 CD ROOM.

JACKSON, M.L. Soil chemical analysis - Advanced course. Madison, Prentice-Hall, 1979. 895p.

JACKSON, M.L.; LIM, C.H. \& ZELAZNY, L.W. Oxides, hydroxides, and aluminosilicates. In: KLUTE, A., ed. Methods of soil analysis. Madison, American Society of Agronomy, 1986. p.101-150.

KÄMPF, N. \& SCHWERTMANN, U. The $5 \mathrm{M} \mathrm{NaOH}$ concentration treatment for iron oxides in solis. Clays Clay Miner., 30:40-408, 1982.

KÄMPF, N. \& SCHWERTMANN, U. Goethite and hematite in a climosequence in Southern Brazil and their application in classification of kaolinitic soils. Geoderma, 29:27-39, 1983.

KÄMPF, N.; KLANT, E. \& SCHNEIDER, P. Óxidos de ferro em Latossolos do Brasil Sudeste e Sul. In: REUNIÃO DE CLASSIFICAÇÃO, CORRELAÇÃO DE SOLOS E INTERPRETAÇÃO DE APTIDÃO AGRÍCOLA, 3., Rio de Janeiro, 1988. Anais. Curitiba, Empresa Brasileira de Pesquisa Agropecuária, Serviço Nacional de Levantamento e Classificação do Solo, 1988a. p.153-183.

KÄMPF, N.; RESENDE, M. \& CURI, N. Iron oxides in Brazilian soils. In: INTERNATIONAL SOIL CLASSIFICATION WORSHOP, 8., Curitiba, 1988. Anais. Curitiba, Empresa Brasileira de Pesquisa Agropecuária, Universidade Federal do Paraná, 1988b. p.71-77.

KER, J.C. Caracterização química, física, mineralógica e micromorfológica de solos brunos subtropicais. Viçosa, Universidade Federal de Viçosa, 1988. 148p. (Tese de Mestrado)

KER, J.C. Mineralogia, sorção e desorção de fosfato, magnetização e elementos traços de Latossolos do Brasil. Viçosa, Universidade Federal de Viçosa, 1995. 181p. (Tese de Doutorado)

KLUG, H.P. \& ALEXANDER, L.E. X-ray diffraction procedures for polycrystalline and amorphous materials. New York, John Wiley \& Sons, 1954. 716p.

KOPPI, A.J. \& SKJEMSTAD, J.O. Soil kaolins and their genetic relationships in southeast Queensland. J. Soil Sci., 32:661672,1981 .

LEMOS, R.C. \& SANTOS, R.D. Manual de descrição e coleta de solo no campo. 3.ed. Campinas, Sociedade Brasileira de Ciência do Solo, 1996. 84p.

LIMA, V.C. Caracterização e classificação de solos derivados de eruptivas básicas do terceiro planalto paranaense. Piracicaba, Escola Superior de Agricultura Luiz de Queiroz, 1979. 249p. (Tese de Doutorado)

MAACK, R. Geografia física do Estado do Paraná. Curitiba, 1968. 350p.

McKEAGUE, J.A. Manual on soil sampling and methods of analysis. Ottawa, Canadian Society of Soil Science, 1978. $212 \mathrm{p}$. 
MEHRA, O.P. \& JACKSON, M.L. Iron oxide removal from soils and clay by a dithionite-citrate system bulfered with sodium bicarbonate. Clays Clay Miner., 7:317-327, 1960.

MELO, V.F. Relação entre a reserva de solos e a produção e nutrientes em povoamentos de Eucalyptus saligna Smith, no Rio Grande do Sul. Viçosa, Universidade Federal de Viçosa, 1994. 145p. (Tese de Mestrado)

MELO, V.F.; NOVAIS, R.F.; FONTES, M.P.F. \& SCHAEFER, C.E.G.R. Potássio e magnésio em minerais das frações areia e silte de diferentes solos. R. Bras. Ci. Solo, 24:269-284, 2000.

MELO, V.F.; SINGH, B.; SCHAEFER, C.E.G.R.; NOVAIS, R.F. \& FONTES, M.P.F. Chemical and mineralogical properties of kaolinite-rich Brazilian soils. Soil Sci. Soc. Am. J, 65:13241333, 2001a.

MELO, V.F.; FONTES, M.P.F.; NOVAIS, R.F.; SINGH, B. \& SCHAEFER, C.E.G.R. Características dos óxidos de ferro e de alumínio de diferentes classes de solos. R. Bras. Ci. Solo, 25:19-32, 2001b.

MESQUITA FILHO, M.V. \& TORRENT, J. Phosphate sorption as related to mineralogy of a hidrosequence of soils from the cerrado region (Brazil). Georderma, 58:107-123, 1993.

MESTDAGH, M.M.; VIELVOYE, L. \& HERBILLON, A.J. Iron in kaolinite: II. The relationship between kaolinite crystallinity and iron content. Clay Miner., 15:1-13, 1980.

NETTO, A.R. Influência da mineralogia da fração argila sobre propriedades físico-químicas de solos brasileiros. Viçosa, Universidade Federal de Viçosa, 1996. 144p. (Tese de Mestrado)

NORRISH, K. \& TAYLOR, M. The isomorphous replacement of iron by aluminium in soil goethites. J. Soil Sci., 12:294306, 1961.

PALMIERI, F. A study of a climosequence of soils derived from volcanic rock parent material in Santa Catarina and Rio Grande do Sul states, Brazil. West Lafayette, Purdue University, 1986. 259p. (Tese de Doutorado)

PAVAN, M.A.; BLOCH, M.F.; ZEMPUSKI, H.C.; MIYAZAWA, M. \& ZOCOLER, D.C. Manual de análise química do solo e controle de qualidade. Londrina, IAPAR, 1992. (Circular, 76)

PLANÇON, A. \& ZACHARIE, C. An expert system for the structural characterization of kaolinites. Clay Miner., 25:249-261, 1990.
SANTOS, A.R. Caracterização mineralógica e avaliação da reserva mineral de alguns nutrientes, em solos sob eucalipto, da região do Vale do Rio Doce. Viçosa, Universidade Federal de Viçosa, 1993. 97p. (Tese de Mestrado)

SCHNEIDER, A.W. Vulcanismo basáltico da bacia do Paraná: perfil Foz do Iguaçu - Serra da Esperança. In: CONGRESSO BRASILEIRO GEOLOGIA, 26., Brasília, 1970. Anais. Brasília, Sociedade Brasileira de Geologia, 1970. p.211-217.

SCHULZE, D.G. The influence of aluminium on iron oxides. VIII - Unit-cell dimensions of $\mathrm{Al}$-substituted goethites and estimation of $\mathrm{Al}$ from them. Clays Clay Miner., 32:36:44, 1984.

SCHWERTMANN, U.; FITZPATRICK, R.W.; TAYLOR, R.M. \& LEWIS, D.G. The influence of aluminium on iron oxides. Preparation and properties of Al-substituted hematites. Clays Clay Miner., 29:269-276, 1979.

SCHWERTMANN, U. \& KÄMPF, N. Properties of goethite and hematite in kaolinitic soils of Southern and Central Brazil. Soil Sci., 139:344-350, 1985.

SCHWERTMANN, U. \& TAYLOR, R.M. Iron oxides. In: DIXON, J.B. \& WEED, S.B., eds. Minerals in soil environments. 2.ed. Madison, Soil Science Society of America, 1989. p.380-427.

SCHWERTMANN, U. Ocurrence and formation of iron oxides in various pedoenvironments. In: STUCKI, J.W.; GOODMAN, B.A. \& SCHWERTMANN, V. Iron in soils and clay minerals. Dadrecht, Reidel Publishing Company, 1988. p.267-308.

SINGH, B. \& GILKES, R.J. Concentration of iron oxides from soil clays by $5 \mathrm{M} \mathrm{NaOH}$ treatment: The complete removal of sodalite and kaolin. Clay Miner., 26:463-472, 1991.

SINGH, B. \& GILKES, R.J. Properties of soil kaolinites from South-Westen Australia. J. Soil Sci., 43:645-667, 1992.

TETTENHORST, R.T. \& CORBATÓ, C.E. Properties of a sized an ground kaolinite. Clay Clay. Miner., 21:971-976, 1986.

TORRENT, J. \& CABEDO, A. Sources of iron oxides in reddish brown soil profiles from calcarenites in Southern Spain. Geoderma, 37:5766, 1986.

WHitTIG, L.D. \& ALLARDiCE, W.R. X ray diffraction techniques. In: KLUTE, A., ed. Methods of soil analysis. Madison, American Society of Agronomy, 1986. p.331-362. 